Research Article

\title{
An Equal-Strain Analytical Solution for the Radial Consolidation of Unsaturated Soils by Vertical Drains considering Drain Resistance
}

\author{
Feng Zhou ${ }^{1}$, ${ }^{1}$ Zheng Chen ${ }^{(D)},{ }^{2,3}$ and Xudong Wang ${ }^{1}$ \\ ${ }^{1}$ College of Transportation Science \& Engineering, Nanjing Tech University, Nanjing 210009, China \\ ${ }^{2}$ State Key Laboratory of Water Resources and Hydropower Engineering Science, Wuhan University, Wuhan 430072, China \\ ${ }^{3}$ Key Laboratory of Rock Mechanics in Hydraulic Structural Engineering, Ministry of Education, Wuhan University, \\ Wuhan 430072, China \\ Correspondence should be addressed to Zheng Chen; johnchan@whu.edu.cn
}

Received 6 November 2017; Revised 27 January 2018; Accepted 6 February 2018; Published 12 April 2018

Academic Editor: Fan Gu

Copyright (c) 2018 Feng Zhou et al. This is an open access article distributed under the Creative Commons Attribution License, which permits unrestricted use, distribution, and reproduction in any medium, provided the original work is properly cited.

Developing an analytical solution for the consolidation of unsaturated soils remains a challenging task due to the complexity of coupled governing equations for air and water phases. This paper presents an equal-strain model for the radial consolidation of unsaturated soils by vertical drains, and the effect of drain resistance is also considered. Simplified governing equations are established, and an analytical solution to calculate the excess pore-air and pore-water pressures is derived by using the methods of matrix analysis and eigenfunction expansion. The average degrees of consolidation for air and water phases and the ground surface settlement are also given. The solutions of the equal-strain model are verified by comparing the proposed free-strain model with the equal-strain model, and reasonably good agreement is obtained. Moreover, parametric studies regarding the drain resistance effect are graphically presented.

\section{Introduction}

As a common phenomenon of civil engineering, consolidation is a process of decreasing soil volume when soil is subjected to an increased stress. Understanding of this phenomenon is vital to designs of soft soil foundations, pavements, and other engineering structures. Therefore, Terzaghi [1] established a classical theory for the analysis of consolidation in saturated soft soil foundation, which is well known in geotechnical engineering. Based on Terzaghi's theory, solutions of one-dimensional consolidation have been derived for multilayered soils [2,3], non-Darcy flow $[4,5]$, time-dependent loading [6, 7], arbitrary boundary $[8,9]$, and nonlinear deformation $[10,11]$. In practice, soft soils related to engineering are usually in a state of unsaturation. With the great progress made, some well-developed consolidation theories for unsaturated soft soils have been available [12-15]. Among these theories, Fredlund and Rahardjo's [15] consolidation theory is well accepted for the consolidation of unsaturated soft soils.

Since the inception of the one-dimensional (1D) consolidation theory of unsaturated soft soils proposed by Fredlund and Hasan [16], the investigations for 1D consolidation have been significantly progressed. By assuming constant soil parameters during consolidation, Qin et al. $[17,18]$ adopted the Laplace transform and Cayley-Hamilton methods to obtain an analytical solution. Shan et al. [19] and Zhou et al. [20] converted the nonlinear governing flow equations into traditional diffusion equations and proposed alternative solutions satisfying those converted equations. Ho et al. [21], on the other hand, introduced exact solutions using the eigenfunction expansion and Laplace transform techniques. In addition, some general solutions that consider various boundary conditions $[9,19,20,22]$, initial pore-water and -air pressure distributions $[9,20]$, and complex timedependent loadings $[9,19,20,22-24]$ were also obtained in a single soil layer. However, the soft soil foundation in practice 
is not always singly layered. For this reason, Shan [25] presented an analytical solution of unsaturated multilayered soil with typical boundary conditions.

In subgrade and pavement engineering, vertical drains are one of the most commonly used techniques to accelerate the consolidation process and increase the bearing capacity of the subgrade. It is essential to expand the consolidation theory of unsaturated soft soils from one-dimensional vertical consolidation to radial consolidation. For this purpose, Conte [26] developed a general formulation that can be advantageously used to analyze consolidation under plane-strain conditions. Ho et al. [27] discussed the excess pore-air and pore-water pressure dissipations in the plane-strain consolidation of unsaturated soft soils using eigenfunction expansion and Laplace transform techniques. Shortly afterwards, the solutions of unsaturated soft soils subjected to different time-dependent loadings were also obtained by Ho [28].

However, a lot of attempts have been made to solve the axisymmetric consolidation model of unsaturated soft soils particularly with analytical approaches. Among the pioneered studies, Conte [26] introduced the finite element technique to obtain a solution for the coupled consolidation under the axisymmetric conditions. Qin et al. [29] dealt with the vertical drain consolidation problem in unsaturated soft soils using the modified Bessel functions and the Laplace transformation. On the other hand, Zhou and Tu [30] and Zhou [31] presented the differential quadrature method (DQM) to estimate the axisymmetric consolidation behavior in the unsaturated soft soils. Ho et al. [32] gave an analytical solution for the axisymmetric consolidation of unsaturated soft soils subjected to constant external loading. The analytical procedure employs the variable separation and Laplace transformation techniques while capturing the uniform and linear initial excess pore pressure distributions with depth.

Most of the models mentioned above were obtained based on the free-strain assumption. However, the solutions of the free-strain model are complex and inconvenient to use in practice. In the research of saturated soft soils, Barron [33] firstly proposed the consolidation model for vertical drains under free-strain and equal-strain models. The mathematical expressions are as follows:

$$
\begin{aligned}
& c_{\mathrm{r}}\left(\frac{\partial^{2} u}{\partial r^{2}}+\frac{1}{r} \cdot \frac{\partial u}{\partial r}\right)+c_{\mathrm{v}} \frac{\partial^{2} u}{\partial z^{2}}=\frac{\partial u}{\partial t} \quad \text { (free-strain model), } \\
& c_{\mathrm{r}}\left(\frac{\partial^{2} u}{\partial r^{2}}+\frac{1}{r} \cdot \frac{\partial u}{\partial r}\right)+c_{\mathrm{v}} \frac{\partial^{2} u}{\partial z^{2}}=\frac{\partial \bar{u}}{\partial t} \quad \text { (equal-strain model) }
\end{aligned}
$$

where $u$ and $\bar{u}$ are the excess pore-water pressure and average excess pore-water pressure, respectively; $c_{\mathrm{r}}$ and $c_{\mathrm{v}}$ are the coefficients of consolidation in the radial and vertical directions, respectively; $r$ is the distance from the origin of the vertical drain in the radial direction; $z$ is the distance from the surface of the foundation in the vertical direction; and $t$ is the time. Barron [33] pointed out that there is negligible difference between the free-strain and equal-strain models. After this, equal-strain assumption is frequently used in most consolidation theories for vertical drains [34-36].

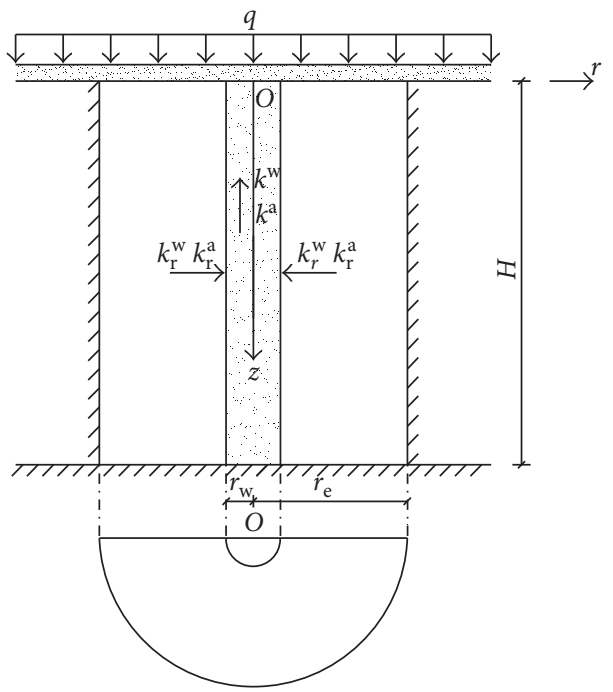

FIgURE 1: Calculation diagram of vertical drain in an unsaturated soil stratum.

At present, there is no reference about the equal-strain model in the research of unsaturated soft soils. The objective of this paper is to propose an equal-strain consolidation model to investigate the consolidation behavior of unsaturated soft soils. In addition, drain resistance will also be considered in this study, and the accuracy of the equal-strain model will be verified by comparing with the free-strain model proposed by Qin et al. [29]. Moreover, parametric studies regarding the drain resistance effect are also presented in this paper.

\section{Problem Statements}

2.1. Model Description. Figure 1 describes the details of the representative vertical drain within an unsaturated soft soil foundation. Dimensions of the soil system include the depth $H$ and the radius of the influence zone $r_{\mathrm{e}} . k_{\mathrm{r}}^{\mathrm{w}}$ and $k_{\mathrm{r}}^{\mathrm{a}}$ are the coefficients of water and air permeability of the foundation in the radial direction, respectively. The circular vertical drain with the radius $r_{\mathrm{w}}$ is installed at the center of the influence zone. $k^{\mathrm{w}}$ and $k^{\mathrm{a}}$ are the coefficients of water and air permeability of the vertical drain in the vertical direction, respectively. A constant surcharge $q$ is instantaneously applied on the top surface of soft soil foundation.

2.2. Basic Assumptions. The basic assumptions are the same as those of Fredlund's consolidation theory for unsaturated soft soils and Barron's [33] consolidation theory for vertical drains. The other three assumptions are listed as follows:

(1) All the soil parameters are constants during consolidation.

(2) The strains at the same depth of the foundation are equal (equal-strain assumption).

(3) The distribution of excess pore-air pressure in unsaturated soft soils is uniform. 
2.3. Derivation of Consolidation Governing Equations. The governing equations for the consolidation of unsaturated soft soils with vertical drains consist of water phase and air phase equations under equal-strain conditions. In the polar coordinate system, considering a representative element of unsaturated soft soil foundation, with water and air flow in and out in the radial direction during consolidation, the derivation process is given as follows.

2.3.1. Water Phase. The net flux of water through the element is computed from the volume of water entering and leaving the element within a period of time. By utilizing Darcy's law, the net flux of water per unit volume of the soil can be expressed in the polar coordinate system as

$$
\frac{\partial\left(V_{\mathrm{w}} / V_{0}\right)}{\partial t}=\frac{k_{\mathrm{r}}^{\mathrm{w}}}{\gamma_{\mathrm{w}}}\left(\frac{\partial^{2} u_{\mathrm{w}}}{\partial r^{2}}+\frac{1}{r} \cdot \frac{\partial u_{\mathrm{w}}}{\partial r}\right)
$$

where $V_{0}$ is the initial total volume of the soil element, $V_{\mathrm{w}}$ is the volume of water in the soil element, $\gamma_{\mathrm{w}}$ is the unit weight of water, and $u_{\mathrm{w}}$ is the excess pore-water pressure.

The net flux of water per unit volume of the soil can be obtained by differentiating the water phase constitutive relation with respect to time:

$$
\frac{\partial\left(V_{\mathrm{w}} / V_{0}\right)}{\partial t}=m_{1 \mathrm{k}}^{\mathrm{w}} \frac{\partial\left(q-\bar{u}_{\mathrm{a}}\right)}{\partial t}+m_{2}^{\mathrm{w}} \frac{\partial\left(\bar{u}_{\mathrm{a}}-\bar{u}_{\mathrm{w}}\right)}{\partial t},
$$

where $m_{1 \mathrm{k}}^{\mathrm{w}}$ and $m_{2}^{\mathrm{w}}$ describe the coefficients of water volume change with respect to a change in the net normal stress $d\left(q-\bar{u}_{\mathrm{a}}\right)$ and matric suction $d\left(\bar{u}_{\mathrm{a}}-\bar{u}_{\mathrm{w}}\right)$, respectively; and $\bar{u}_{\mathrm{w}}$ and $\bar{u}_{\mathrm{a}}$ are the average excess pore-water and pore-air pressures throughout the entire soil mass, respectively, which can be expressed as

$$
\begin{gathered}
\bar{u}_{\mathrm{w}}=\frac{1}{\pi\left(r_{\mathrm{e}}^{2}-r_{\mathrm{w}}^{2}\right)} \int_{r_{\mathrm{w}}}^{r_{\mathrm{e}}} 2 \pi r u_{\mathrm{w}} \mathrm{dr}, \\
\bar{u}_{\mathrm{a}}=\frac{1}{\pi\left(r_{\mathrm{e}}^{2}-r_{\mathrm{w}}^{2}\right)} \int_{r_{\mathrm{w}}}^{r_{\mathrm{e}}} 2 \pi r u_{\mathrm{a}} \mathrm{dr},
\end{gathered}
$$

where $u_{\mathrm{a}}$ is the excess pore-air pressure.

Substituting (2) into (3), the governing equation for the water phase can be expressed as

$$
\frac{\partial \bar{u}_{\mathrm{w}}}{\partial t}+C_{\mathrm{a}}^{\mathrm{w}} \frac{\partial \bar{u}_{\mathrm{a}}}{\partial t}+C_{\mathrm{r}}^{\mathrm{w}}\left(\frac{\partial^{2} u_{\mathrm{w}}}{\partial r^{2}}+\frac{1}{r} \cdot \frac{\partial u_{\mathrm{w}}}{\partial r}\right)=0,
$$

where $C_{\mathrm{r}}^{\mathrm{w}}$ is the coefficient of consolidation with respect to the water phase in the radial direction (i.e., $\left.k_{\mathrm{r}}^{\mathrm{w}} /\left(\gamma_{\mathrm{w}} m_{2}^{\mathrm{w}}\right)\right)$ and $C_{\mathrm{a}}^{\mathrm{w}}$ is the interactive constant associated with the water phase (i.e., $\left.\left(m_{1 \mathrm{k}}^{\mathrm{w}}-m_{2}^{\mathrm{w}}\right) / m_{2}^{\mathrm{w}}\right)$.

2.3.2. Air Phase. The net flux of air through the element is computed from the volume of air entering and leaving the element within a period of time. The flux of air per unit volume of the soil can be obtained by Fick's law as

$$
\frac{\partial\left(\rho_{\mathrm{a}} V_{\mathrm{a}} / V_{0}\right)}{\partial t}=\frac{k_{\mathrm{r}}^{\mathrm{a}}}{g}\left(\frac{\partial^{2} u_{\mathrm{a}}}{\partial r^{2}}+\frac{1}{r} \cdot \frac{\partial u_{\mathrm{a}}}{\partial r}\right)
$$

where $\rho_{\mathrm{a}}$ is the density of air, $g$ is the gravitational acceleration, and $V_{\mathrm{a}}$ is the volume of air phase.

Based on assumption 3, the distribution of excess poreair pressure in unsaturated soft soils is uniform. The density of air is a function of air pressure in accordance with the ideal gas law. It can be expressed as

$$
\rho_{\mathrm{a}}=\frac{\omega_{a}}{R T_{\mathrm{at}}} \widetilde{u}_{\mathrm{a}}
$$

where $\omega_{\mathrm{a}}$ is the molecular mass of air, $R$ is the molar gas constant, $T_{\text {at }}$ is the absolute temperature, $\widetilde{u}_{\mathrm{a}}$ is the absolute excess pore-air pressure (i.e., $\bar{u}_{\mathrm{a}}+u_{\mathrm{atm}}$ ), and $u_{\mathrm{atm}}$ is the atmospheric pressure.

Replacing the air density, $\rho_{\mathrm{a}}$, in (6) with (7) gives

$$
\frac{\partial\left(V_{\mathrm{a}} / V_{0}\right)}{\partial t}=\frac{k_{\mathrm{r}}^{\mathrm{a}} R T_{\mathrm{at}}}{\tilde{u}_{\mathrm{a}} \omega_{\mathrm{a}} g}\left(\frac{\partial^{2} u_{\mathrm{a}}}{\partial r^{2}}+\frac{1}{r} \cdot \frac{\partial u_{\mathrm{a}}}{\partial r}\right)-\frac{\left(1-S_{\mathrm{s}}\right) n_{\mathrm{s}}}{\widetilde{u}_{\mathrm{a}}} \cdot \frac{\partial \bar{u}_{\mathrm{a}}}{\partial t},
$$

where $S_{\mathrm{s}}$ is the degree of saturation and $n_{\mathrm{s}}$ is the porosity.

The flux of air per unit volume of the soil due to changes in the net normal stress, $d\left(q-\bar{u}_{\mathrm{a}}\right)$, and the matric suction, $d\left(\bar{u}_{\mathrm{a}}-\bar{u}_{\mathrm{w}}\right)$, can be expressed by the following equation:

$$
\frac{\partial\left(V_{\mathrm{a}} / V_{0}\right)}{\partial t}=m_{1 \mathrm{k}}^{\mathrm{a}} \frac{\partial\left(q-\bar{u}_{\mathrm{a}}\right)}{\partial t}+m_{2}^{\mathrm{a}} \frac{\partial\left(\bar{u}_{\mathrm{a}}-\bar{u}_{\mathrm{w}}\right)}{\partial t},
$$

where $m_{1 \mathrm{k}}^{\mathrm{a}}$ and $m_{2}^{\mathrm{a}}$ describe the coefficients of air volume change with respect to a change in the net normal stress $d\left(q-\bar{u}_{\mathrm{a}}\right)$ and matric suction $d\left(\bar{u}_{\mathrm{a}}-\bar{u}_{\mathrm{w}}\right)$, respectively.

By substituting (8) into (9), the governing equation for the air phase can be given as

$$
C_{\mathrm{w}}^{\mathrm{a}} \frac{\partial \bar{u}_{\mathrm{w}}}{\partial t}+\frac{\partial \bar{u}_{\mathrm{a}}}{\partial t}+C_{\mathrm{r}}^{\mathrm{a}}\left(\frac{\partial^{2} u_{\mathrm{a}}}{\partial r^{2}}+\frac{1}{r} \cdot \frac{\partial u_{\mathrm{a}}}{\partial r}\right)=0,
$$

where $C_{r}^{\mathrm{a}}$ is the coefficient of consolidation with respect to the air phase in the radial direction (i.e., $k_{\mathrm{r}}^{\mathrm{a}} R T_{\mathrm{at}} /$ $\left.\left\{\omega_{\mathrm{a}} g\left[\widetilde{u}_{\mathrm{a}}\left(m_{1 \mathrm{k}}^{\mathrm{a}}-m_{2}^{\mathrm{a}}\right)-\left(1-S_{\mathrm{s}}\right) n_{\mathrm{s}}\right]\right\}\right)$ and $C_{\mathrm{w}}^{\mathrm{a}}$ is the interactive constant associated with the air phase (i.e., $m_{2}^{\mathrm{a}} \widetilde{u}_{\mathrm{a}}$ / $\left.\left[\widetilde{u}_{\mathrm{a}}\left(m_{1 \mathrm{k}}^{\mathrm{a}}-m_{2}^{\mathrm{a}}\right)-\left(1-S_{\mathrm{s}}\right) n_{\mathrm{s}}\right]\right)$.

By rearranging the governing equations of water and air phases, the consolidation equations for water and air phases can be written in matrix form as

$$
\mathbf{K}_{\mathrm{r}}\left(\mathbf{u}_{, r r}+\frac{1}{r} \mathbf{u}_{, r}\right)+\mathbf{C} \overline{\mathbf{u}}_{, t}=0,
$$

where $\overline{\mathbf{u}}=\left\{\begin{array}{c}\bar{u}_{\mathrm{w}} \\ \bar{u}_{\mathrm{a}}\end{array}\right\}, \mathbf{u}=\left\{\begin{array}{l}u_{\mathrm{w}} \\ u_{\mathrm{a}}\end{array}\right\}, \mathbf{C}=\left[\begin{array}{cc}1 & C_{\mathrm{a}}^{\mathrm{w}} \\ C_{\mathrm{w}}^{\mathrm{a}} & 1\end{array}\right], \mathbf{K}_{\mathrm{r}}=\left[\begin{array}{cc}C_{\mathrm{r}}^{\mathrm{w}} & 0 \\ 0 & C_{\mathrm{r}}^{\mathrm{a}}\end{array}\right]$, and ()$_{, r}$ and ()$_{, t}$ denote the derivatives with respect to $r$ and $t$, respectively.

2.4. Initial and Boundary Conditions. The external radius, $r_{\mathrm{e}}$, is impervious or, because of symmetry, no water and air flow passes this boundary; that is,

$$
\left.\mathbf{u}_{, r}\right|_{r=r_{\mathrm{e}}}=0 \text {. }
$$


Excess pore pressures at the interface of soil stratum and vertical drain satisfy flow continuity condition. The following boundary condition is considered:

$$
\left.\left(\mathbf{u}_{, r}+\frac{r_{w}}{2} \mathbf{B u}_{, z z}\right)\right|_{r=r_{\mathrm{w}}}=0
$$

where $\mathbf{B}=\left[\begin{array}{cc}k^{\mathrm{w}} / k_{r}^{\mathrm{w}} & 0 \\ 0 & k^{\mathrm{a}} / k_{\mathrm{r}}^{\mathrm{a}}\end{array}\right]$.

The vertical boundary conditions are

$$
\begin{aligned}
\left.\mathbf{u}\right|_{z=0} & =0, \\
\left.\mathbf{u}_{, z}\right|_{z=H} & =0,
\end{aligned}
$$

which indicate that the top surface of the soft soil foundation is permeable to water and air, while the bottom surface is impermeable to water and air.

The initial excess pore pressures are uniform throughout the soil mass when $t=0$. They can be calculated according to the method given by Fredlund and Rahardjo [15]. The initial condition is given as follows:

where $\mathbf{u}_{0}=\left\{\begin{array}{l}u_{0}^{\mathrm{w}} \\ u_{0}^{\mathrm{a}}\end{array}\right\}$.

$$
\left.\overline{\mathbf{u}}\right|_{t=0}=\mathbf{u}_{0},
$$

\section{Solution of the Problem}

3.1. General Solution. According to the boundary condition (12), $\mathbf{u}_{r}$ has to vanish as $r$ goes to $r_{\mathrm{e}}$. An integration of (11) with respect to $r$ from $r$ to $r_{\mathrm{e}}$ gives

$$
\mathbf{u}_{, r}=\varphi(r) \mathbf{K}_{\mathrm{r}}^{-1} \mathbf{C} \overline{\mathbf{u}}_{, t},
$$

where $\varphi(r)=1 / 2\left(\left(r_{\mathrm{e}}^{2} / r\right)-r\right)$.

Then, an integration of (16) with respect to $r$ in interval $\left[r_{\mathrm{w}}, r\right]$ results in

$$
\mathbf{u}=\left.\mathbf{u}\right|_{r=r_{\mathrm{w}}}+\phi(r) \mathbf{K}_{\mathrm{r}}^{-1} \mathbf{C} \overline{\mathbf{u}}_{, t}
$$

where $\phi(r)=\left[(1 / 2) r_{\mathrm{e}}^{2} \ln \left(r / r_{\mathrm{w}}\right)\right]-\left[(1 / 4)\left(r^{2}-r_{\mathrm{w}}^{2}\right)\right]$.

Incorporating (17) into (4) to replace $\mathbf{u}$ for $\overline{\mathbf{u}}$, we have

$$
\overline{\mathbf{u}}=\left.\mathbf{u}\right|_{r=r_{\mathrm{w}}}+\psi \mathbf{K}_{\mathrm{r}}^{-1} \mathbf{C} \bar{u}_{, t}
$$

where $\psi=\left(r_{\mathrm{w}}^{2} / n^{2}-1\right)\left((1 / 2) n^{4} \ln n-(3 / 8) n^{4}+(1 / 2) n^{2}-(1 / 8)\right)$.

The boundary condition of $\mathbf{u}_{, z z}$ at $r_{\mathrm{w}}$ can be expressed as follows by combining (13) and (16):

$$
\left.\mathbf{u}_{, z z}\right|_{r=r_{\mathrm{w}}}=-\frac{2 \varphi\left(r_{\mathrm{w}}\right)}{r_{\mathrm{w}}} \mathbf{B}^{-1} \mathbf{K}_{\mathrm{r}}^{-1} \mathbf{C} \overline{\mathbf{u}}_{, t} .
$$

Substituting (19) into (18) results in

$$
\left.\mathbf{u}_{, z z}\right|_{r=r_{\mathrm{w}}}=\frac{1}{\kappa^{2}} \mathbf{B}^{-1}\left(\left.\mathbf{u}\right|_{r=r_{\mathrm{w}}}-\overline{\mathbf{u}}\right)
$$

where $\kappa=\left(r_{\mathrm{w}} / n^{2}-1\right) \sqrt{(1 / 2) n^{4} \ln n-(3 / 8) n^{4}+(1 / 2) n^{2}-(1 / 8)}$.

General solution for $\left.\mathbf{u}\right|_{r=r_{\mathrm{w}}}$ can be written as products of functions with respect to dimensions $z$ and time $t$. In addition, based on the homogeneous boundary conditions for the depth given in (14), the eigenfunction of $\left.\mathbf{u}\right|_{r=r_{w}}$ is $\sin (M z / H)$. Hence,

$$
\left.\mathbf{u}\right|_{r=r_{\mathrm{w}}}=\sum_{m=1}^{\infty} \frac{2}{M} \sin \frac{M z}{H}\left[\left(\frac{\kappa M}{H}\right)^{2} \mathbf{B}+\mathbf{I}\right]^{-1} \mathbf{T},
$$

where $\mathbf{I}$ is the identity matrix and $M=[(2 m-1) / 2] \pi$.

The average excess pore pressure $\overline{\mathbf{u}}$ can be written as follows by substituting (21) into (20):

$$
\overline{\mathbf{u}}=\sum_{m=1}^{\infty} \frac{2}{M} \sin \frac{M z}{H} \mathbf{T}
$$

By substituting (21) and (22) into (18), the characteristic equation can be obtained using the orthogonality of sine function, as shown below:

$$
\mathbf{T}_{, t}=\frac{1}{\psi} \mathbf{C}^{-1} \mathbf{K}_{\mathrm{r}}\left\{\mathbf{I}-\left[\left(\frac{\kappa M}{H}\right)^{2} \mathbf{B}+\mathbf{I}\right]^{-1}\right\} \mathbf{T} .
$$

Based on the orthogonality of the sine function, the initial condition of $\mathbf{T}$ can be obtained by the initial condition of $\overline{\mathbf{u}}$ as

$$
\left.\mathbf{T}\right|_{t=0}=\mathbf{u}_{0}
$$

According to the initial condition (24), (23) can be solved as

$$
\mathbf{T}=e^{-\mathbf{D} t} \mathbf{u}_{0},
$$

where $\mathbf{D}=(1 / \psi) \mathbf{C}^{-1} \mathbf{K}_{\mathrm{r}}\left\{\left[(\kappa M / \mathrm{H})^{2} \mathbf{B}+\mathbf{I}\right]^{-1}-\mathbf{I}\right\}$.

Combining (21), (22), and (25) and substituting (21) and (22) into (17) give the solutions of $\overline{\mathbf{u}}$ and $\mathbf{u}$ as shown below:

$$
\begin{aligned}
\overline{\mathbf{u}} & =\sum_{m=1}^{\infty} \frac{2}{M} \sin \frac{M z}{H} e^{-\mathbf{D} t} \mathbf{u}_{0}, \\
\mathbf{u} & =\sum_{m=1}^{\infty} \frac{2}{M} \sin \frac{M z}{H} \\
& \times\left\{\left[1-\frac{\phi(r)}{\psi}\right]\left[\left(\frac{\kappa M}{H}\right)^{2} \mathbf{B}+\mathbf{I}\right]^{-1}+\frac{\phi(r)}{\psi} \mathbf{I}\right\} e^{-\mathbf{D} t} \mathbf{u}_{0} .
\end{aligned}
$$

After solving $\overline{\mathbf{u}}$, the average degree of consolidation for water and air phases (i.e., $\mathbf{U}_{\mathrm{e}}=\left(\begin{array}{c}U_{\mathrm{we}} \\ U_{\mathrm{ae}}\end{array}\right)$ ) can be obtained as follows:

$$
\mathbf{U}_{\mathrm{e}}=\mathbf{F}-\frac{1}{H} \mathbf{E}^{-1} \int_{0}^{H} \overline{\mathbf{u}} \mathrm{d} z=\mathbf{F}-\mathbf{E}^{-1} \sum_{m=1}^{\infty} \frac{2}{M^{2}} e^{-\mathbf{D} t} \mathbf{u}_{0},
$$

where $\mathbf{E}=\left[\begin{array}{cc}u_{0}^{\mathrm{w}} & 0 \\ 0 & u_{0}^{\mathrm{a}}\end{array}\right]$ and $\mathbf{F}=\left\{\begin{array}{l}1 \\ 1\end{array}\right\}$.

Based on Fredlund's theory, the volume change is given by the following constitutive equation for unsaturated soft soils [15]:

$$
\frac{\partial \varepsilon_{\mathrm{v}}}{\partial t}=m_{1 \mathrm{k}}^{\mathrm{s}} \frac{\partial\left(q-\bar{u}_{\mathrm{a}}\right)}{\partial t}+m_{2}^{\mathrm{s}} \frac{\partial\left(\bar{u}_{\mathrm{a}}-\bar{u}_{\mathrm{w}}\right)}{\partial t}
$$


where $\varepsilon_{\mathrm{v}}$ is the volumetric strain, $m_{1 \mathrm{k}}^{\mathrm{s}}=m_{\mathrm{lk}}^{\mathrm{w}}+m_{1 \mathrm{k}}^{\mathrm{a}}$ is the coefficient of volume change with respect to a change in net normal stress, and $m_{2}^{\mathrm{s}}=m_{2}^{\mathrm{w}}+m_{2}^{\mathrm{a}}$ is the coefficient of volume change with respect to a change in matric suction.

The ground surface settlement $S_{\mathrm{e}}$ of the unsaturated soft soil can be computed as

$$
S_{\mathrm{e}}=\int_{0}^{H} \int_{0}^{t} \frac{\partial \varepsilon_{\mathrm{v}}}{\partial t} \mathrm{~d} t \mathrm{~d} z=H \mathbf{G}\left(\mathbf{I}-\sum_{m=1}^{\infty} \frac{2}{M^{2}} e^{-\mathbf{D} t}\right) \mathbf{u}_{0},
$$

where $\mathbf{G}=\left\{\begin{array}{ll}m_{2}^{\mathrm{s}} & m_{1 \mathrm{k}}^{\mathrm{s}}-m_{2}^{\mathrm{s}}\end{array}\right\}$.

The normalized settlement, denoted as $S_{\text {ne }}$, can be determined based on the volumetric strain $\varepsilon_{\mathrm{v}}$ provided in (30):

$$
S_{\text {ne }}=\frac{S_{\mathrm{e}}}{S_{\mathrm{e}}^{\infty}}=\frac{1}{\mathbf{G u}_{0}} \mathbf{G}\left(\mathbf{I}-\sum_{m=1}^{\infty} \frac{2}{M^{2}} \mathrm{e}^{-\mathbf{D} t}\right) \mathbf{u}_{0},
$$

where $S_{\mathrm{e}}^{\infty}$ is the ultimate ground surface settlement when the pore pressures dissipated entirely (i.e., $S_{\mathrm{e}}^{\infty}=$ $\left.H\left[m_{1 \mathrm{k}}^{\mathrm{s}} u_{0}^{\mathrm{a}}+m_{2}^{\mathrm{s}}\left(u_{0}^{\mathrm{w}}-u_{0}^{\mathrm{a}}\right)\right]\right)$. As can be seen from (31), $S_{\text {ne }}$ is also the total degree of consolidation which is dominated by both air and water phases.

3.2. A Special Case. When the effect of drain resistance is neglected, the permeability of drain well is endless, videlicet $k^{\mathrm{w}}$ and $k^{\mathrm{a}}$ tend towards infinity, which yields $\left[(\kappa M / H)^{2} \mathbf{B}+\mathbf{I}\right]^{-1} \rightarrow 0$. Parameter $\mathbf{D}$ can be rewritten as

$$
\mathbf{D}=-\frac{1}{\psi} \mathbf{C}^{-1} \mathbf{K}_{\mathrm{r}} .
$$

Based on the theory of series, the following can be obtained:

$$
\sum_{m=1}^{\infty} \frac{2}{M} \sin \frac{M z}{H}=\sum_{m=1}^{\infty} \frac{2}{M^{2}}=1 \quad(0<z \leq H) .
$$

By substituting (32) and (33) into (26-28) and (30) and (31), the solutions can be simplified to

$$
\begin{aligned}
\overline{\mathbf{u}} & =e^{(1 / \psi) \mathbf{C}^{-1} \mathbf{K}_{\mathrm{r}} t} \mathbf{u}_{0}, \\
\mathbf{u} & =\frac{\phi(r)}{\psi} e^{(1 / \psi) \mathbf{C}^{-1} \mathbf{K}_{\mathrm{r}} t} \mathbf{u}_{0}, \\
\mathbf{U}_{\mathrm{e}} & =\mathbf{F}-\mathbf{E}^{-1} e^{(1 / \psi) \mathbf{C}^{-1} \mathbf{K}_{\mathrm{r}} t} \mathbf{u}_{0}, \\
S_{\mathrm{e}} & =H \mathbf{G}\left(\mathbf{I}-e^{(1 / \psi) \mathbf{C}^{-1} \mathbf{K}_{\mathrm{r}} t}\right) \mathbf{u}_{0}, \\
S_{\mathrm{ne}} & =\frac{1}{\mathbf{G} \mathbf{u}_{0}} \mathbf{G}\left(\mathbf{I}-e^{(1 / \psi) \mathbf{C}^{-1} \mathbf{K}_{\mathrm{r}} t}\right) \mathbf{u}_{0} .
\end{aligned}
$$

The equations from (34) to (38) are the simplified solutions in which the effect of drain resistance is neglected.

\section{Analysis of Consolidation Behavior}

In this study, the accuracy of the proposed equal-strain consolidation model in the unsaturated soft soils is investigated by comparing with the free-strain model. The consolidation behavior and influence factors are also discussed in this section. Following Fredlund and Rahardjo [15] and Conte [26], the consolidation parameters adopted in this study are listed as follows:

(i) Mechanical parameters

$n_{\mathrm{s}}=0.5, S_{\mathrm{s}}=0.8, \mathrm{~m}_{1 \mathrm{k}}^{\mathrm{w}}=-5 \times 10^{-8} \cdot \mathrm{Pa}^{-1}, m_{2}^{\mathrm{w}}=-2 \times 10^{-7}$. $\mathrm{Pa}^{-1}, m_{1 \mathrm{k}}^{\mathrm{a}}=-2 \times 10^{-7} \cdot \mathrm{Pa}^{-1}, m_{2}^{\mathrm{a}}=10^{-7} \cdot \mathrm{Pa}^{-1}, k_{\mathrm{r}}^{\mathrm{w}}=10^{-10} \mathrm{~m} / \mathrm{s}$, $k_{\mathrm{r}}^{\mathrm{a}}=10^{-7} \mathrm{~m} / \mathrm{s}, k^{\mathrm{w}}=10^{-7} \mathrm{~m} / \mathrm{s}$, and $k^{\mathrm{a}}=10^{-4} \mathrm{~m} / \mathrm{s}$.

(ii) Fundamental constants of physics

$\mathrm{T}_{\text {at }}=298.15 \mathrm{~K}, \quad \mathrm{R}=8.314 \mathrm{~J} / \mathrm{mol} \cdot \mathrm{K}, \quad u_{\mathrm{atm}}=101.3 \mathrm{kPa}$, $\omega_{\mathrm{a}}=29 \mathrm{~g} / \mathrm{mol}, g=9.8 \mathrm{~m} / \mathrm{s}^{2}$, and $\gamma_{\mathrm{w}}=10^{4} \mathrm{~N} / \mathrm{m}^{3}$.

(iii) Geometrical parameters

$r_{\mathrm{w}}=0.2 \mathrm{~m}, r_{\mathrm{e}}=1.8 \mathrm{~m}$, and $H=10 \mathrm{~m}$.

(iv) Other parameters

$q=100 \mathrm{kPa}, u_{0}^{\mathrm{w}}=40 \mathrm{kPa}$, and $u_{0}^{\mathrm{a}}=20 \mathrm{kPa}$.

The above parameters are assumed to be constant during the consolidation process. An instantaneous compression induced by the external applied load $q$ generates initial excess pore-water and pore-air pressures (i.e., $u_{0}^{\mathrm{w}}$ and $u_{0}^{\mathrm{a}}$, resp.). Considering that the soil is loaded threedimensionally under isotropic conditions, changes in excess pore pressures can be determined using a method given by Fredlund and Hasan [16].

4.1. Verification. The validity of the equal-strain model had been verified in the saturated soft soils. In this section, the validity of the proposed equal-strain model in the unsaturated soft soils will be verified as well. For this purpose, the special consolidation case without considering drain resistance is analyzed by using the proposed equal-strain solution and one available free-strain solution [29].

Figures 2(a) and 2(b), respectively, demonstrate changes in the average degrees of consolidation of air and water phases with different ratios of $k_{\mathrm{r}}^{\mathrm{a}} / k_{\mathrm{r}}^{\mathrm{w}}$ under the equal-strain and free-strain conditions. It is worth noting that the air permeability $k_{\mathrm{r}}^{\mathrm{a}}$ is varying while the water permeability $k_{\mathrm{r}}^{\mathrm{W}}$ is kept constant at $10^{-10} \mathrm{~m} / \mathrm{s}$. In addition, the time factor is defined as $T=C_{\mathrm{r}}^{\mathrm{w}} t / H^{2}$. It can be observed from the figures that the results obtained from these two different models are in good agreement with each other. The slightly large difference between the two models is mainly found at the earlier stage of the consolidation process. Moreover, it can be seen that with an increase of $k_{\mathrm{r}}^{\mathrm{a}} / k_{\mathrm{r}}^{\mathrm{w}}$, the average degrees of consolidation increase gradually for both air phase and water phase. With an increase of consolidation time $T$, the curve of average degree of consolidation for water phase gradually tends to be consistent. This is because the pore-air pressure almost completely dissipates at the early stage of consolidation.

Figures 3(a) and 3(b) represent the difference of average consolidation degree between equal-strain model and freestrain model varying with $T$ in different $k_{\mathrm{r}}^{\mathrm{a}} / k_{\mathrm{r}}^{\mathrm{w}}$ values. As observed from Figure 3(a), the maximum difference (slightly more than 3\%) between two models for air phase is mainly at 


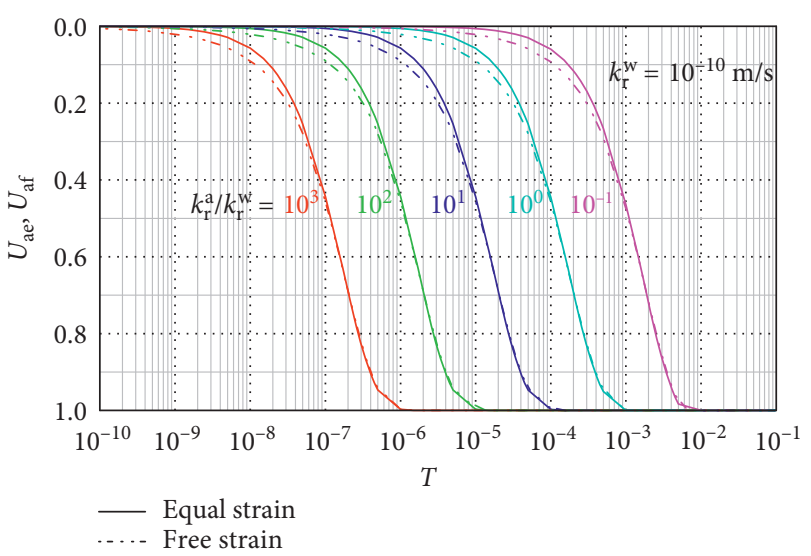

(a)

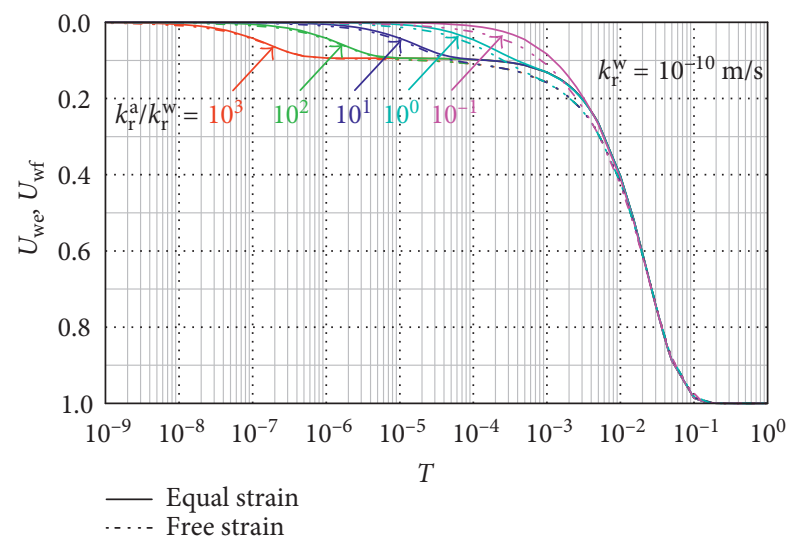

(b)

FIgURE 2: Average degrees of consolidation of (a) air phase and (b) water phase varying with different ratios of $k_{\mathrm{r}}^{\mathrm{a}} / k_{\mathrm{r}}^{\mathrm{w}}$.

the earlier stage of consolidation before the excess porewater pressure begins to dissipate. Inversely, the maximum difference in the water phase is mainly near the end of the air dissipation, as shown in Figure 3(b). In brief, there is negligible influence on the difference between equal-strain condition and free-strain condition with different ratios of $k_{\mathrm{r}}^{\mathrm{a}} / k_{\mathrm{r}}^{\mathrm{w}}$. It shows that the equal-strain model is efficient in solving the unsaturated soil consolidation problem. Also, the solution is convenient for engineering application.

4.2. Influence of Drain Resistance. Figure 4 represents the degrees of consolidation of air and water phases and normalized settlement varying with $T$ under different values of $r_{\mathrm{w}}$. The influence radius $r_{\mathrm{e}}=1.8 \mathrm{~m}$ is adopted in this investigation. Figure 4(a) shows the degrees of consolidation of air phase varying with different values of $r_{\mathrm{w}}$ as time elapses. It is obvious that the consolidation proceeds more quickly with the increase of $r_{\mathrm{w}}$. As the radius of vertical drain increases, the radial drainage area will be indirectly increased, which accelerates the process of consolidation. Figure 4(b) shows the degrees of consolidation of the water phase with different values of $r_{\mathrm{w}}$. As observed, the rate of consolidation of water phase at the initial stage proceeds more quickly because of increasing $r_{\mathrm{w}}$. After the excess pore-air pressure

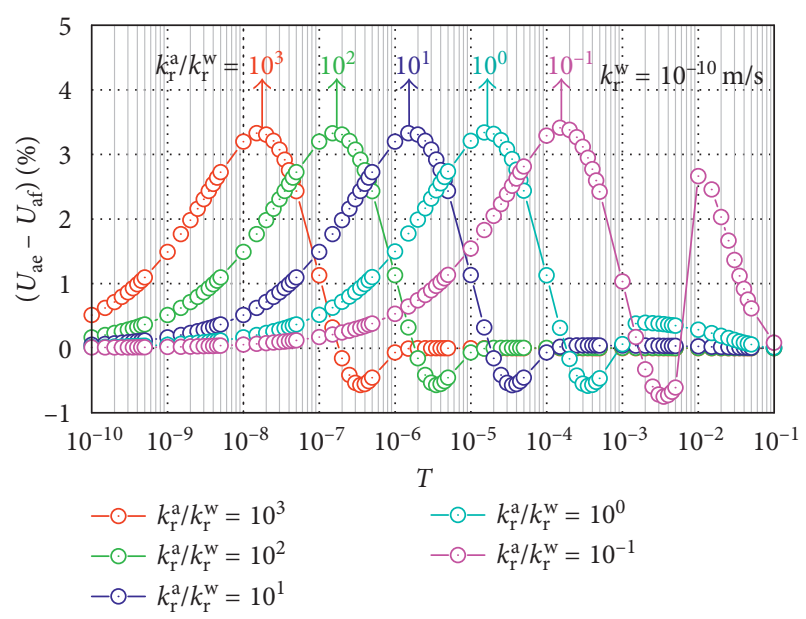

(a)

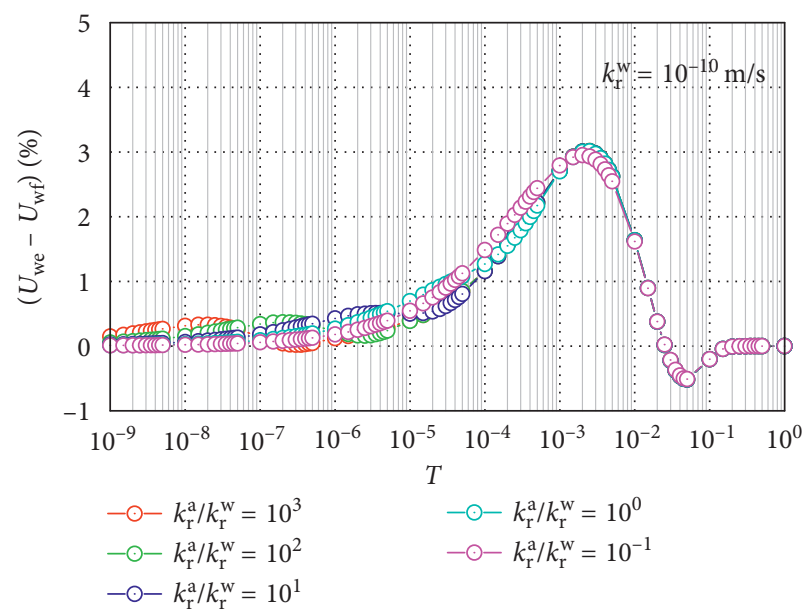

(b)

FIgURE 3: Difference of degrees of consolidation in (a) air phase and (b) water phase varying with different ratios of $k_{\mathrm{r}}^{\mathrm{a}} / k_{\mathrm{r}}^{\mathrm{w}}$.

dissipated almost completely, a plateau period may occur in the excess pore-water pressure patterns. At the later stage, the rate of water phase consolidation is similar to the initial stage. Besides, it can also be found that the excess pore-air pressure dissipated faster than that of the excess pore-water pressure because the permeability of air phase is greater than water phase both in the vertical drain and unsaturated soft soil foundation. Figure 4(c) presents the normalized settlement against time factor $T$ with different values of $r_{\mathrm{w}}$. The settlement process is similar to the consolidation process of water phase.

Figure 5 demonstrates changes in excess pore pressures and normalized settlement with different ratios of $k^{\mathrm{a}} / k^{\mathrm{w}}$. Figure 5(a) illustrates the dissipation curves of excess poreair pressure varying with $T$ in different ratios of $k^{\mathrm{a}} / k^{\mathrm{w}}$. As observed, when $k^{\mathrm{a}} / k^{\mathrm{w}}$ increases, the excess pore-air pressure tends to dissipate faster. When $k^{\mathrm{a}} / k^{\mathrm{w}}$ is very high, for instance, $k^{\mathrm{a}} / k^{\mathrm{w}}=10^{3}$, the excess pore-air pressure may dissipate instantaneously. Figure $5(\mathrm{~b})$ shows the dissipation curves of excess pore-water pressure varying with $k^{\mathrm{a}} / \mathrm{k}^{\mathrm{w}}$ when time elapses. It is evident that the dissipation at the initial stage of consolidation proceeds more quickly as 


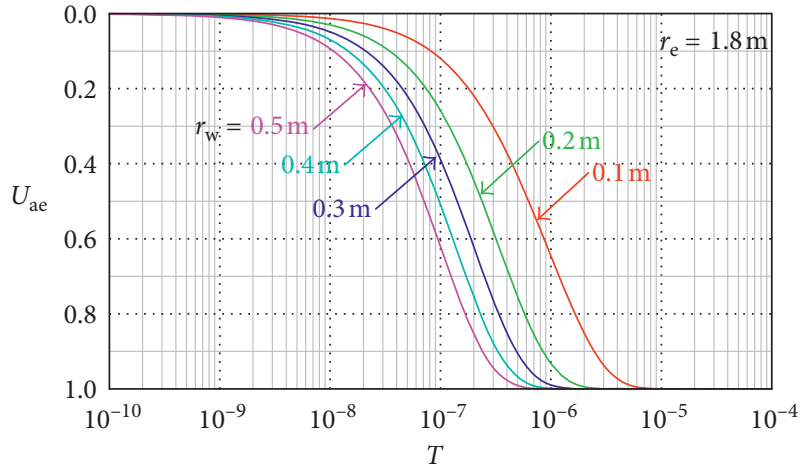

(a)

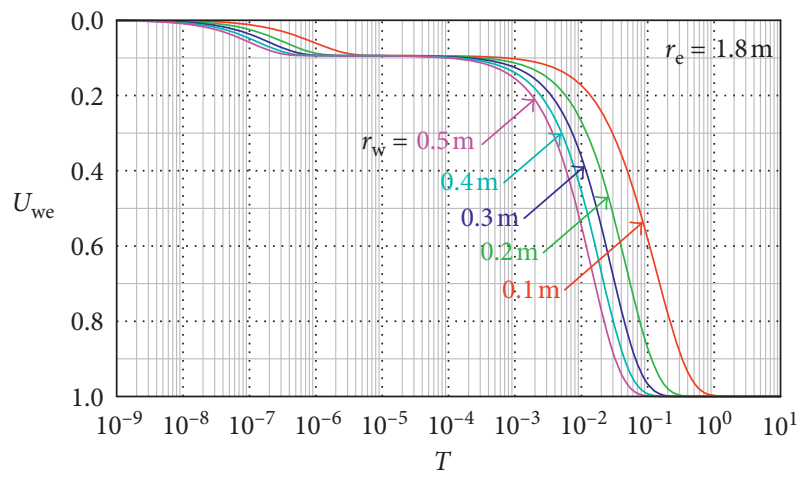

(b)

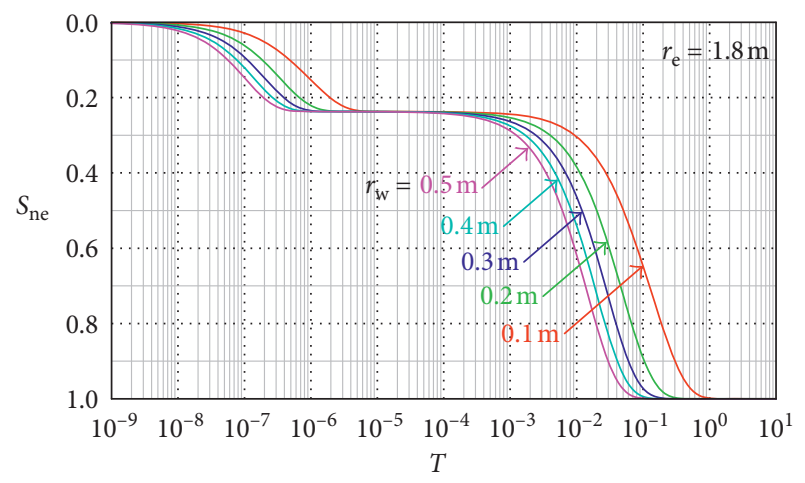

(c)

Figure 4: Degrees of consolidation of (a) air phase, (b) water phase, and (c) normalized settlement varying with different values of $r_{\mathrm{w}}$.

a result of increasing $k^{\mathrm{a}} / k^{\mathrm{w}}$. After the excess pore-air pressure diminished almost fully, a plateau period may occur in the excess pore-water pressure patterns when $k^{\mathrm{a}} / k^{\mathrm{w}}>1$. It should be noted that the greater the ratio of $k^{\mathrm{a}} / k^{\mathrm{w}}$ is, the longer the plateau gets. Lastly, the curves of excess pore-water pressure dissipation converge to a single curve, and complete dissipation occurs at approximately the same time. Figure 5(c) shows the variations of the normalized settlement against time factor $T$ with different ratios of $k^{\mathrm{a}} / k^{\mathrm{w}}$. It is worth noting that $S_{\text {ne }}$ patterns consist of double inverse $S$ curves when $k^{\mathrm{a}} / k^{\mathrm{w}}>0.1$, similar to the excess porewater pressure dissipation process. The initial stage of consolidation is governed by the simultaneous dissipation of both excess pore-air and pore-water pressures, and once the

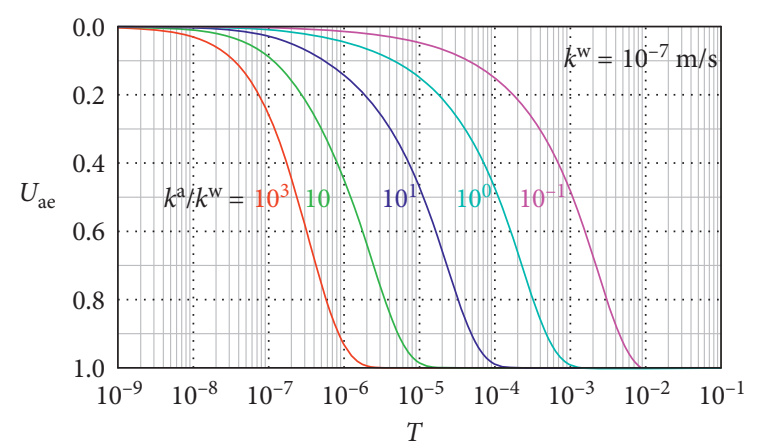

(a)

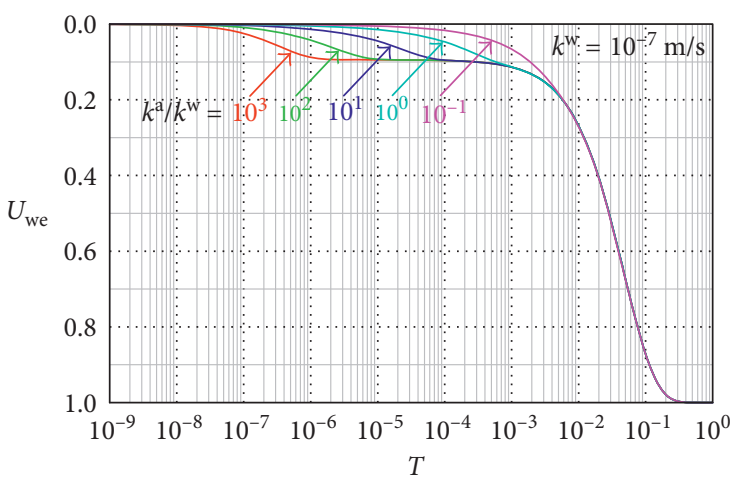

(b)

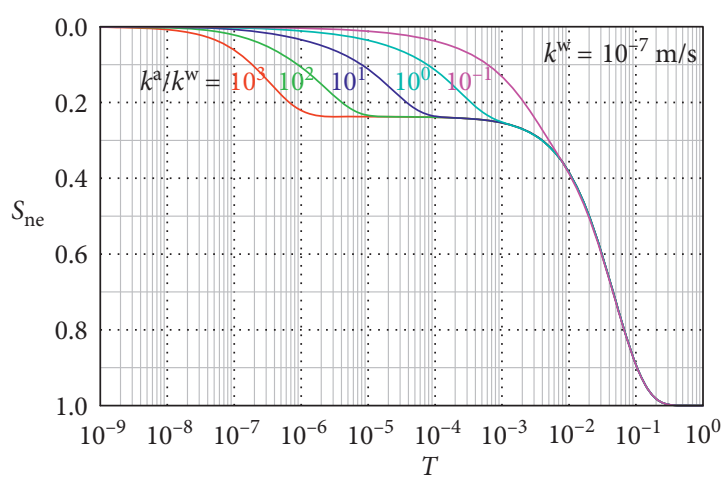

(c)

Figure 5: Degrees of consolidation of (a) air phase, (b) water phase, and (c) normalized settlement varying with different ratios of $k^{\mathrm{a}} / k^{\mathrm{w}}$.

excess pore-air pressure is fully dissipated in the soft soil system, $S_{\text {ne }}$ patterns converge to only one curve and gradually approach 1 at the later stages. More remarkable, after the plateau period, the consolidation behavior is dominated by single phase (water phase) and the consolidation resembles to the classical Terzaghi's consolidation [1].

By comparing Figure 4 with Figure 5, the variation of vertical drain radius makes the normalized settlement $S_{\text {ne }}$ a great change in the whole period of consolidation. In contrast, the difference of normalized settlement $S_{\text {ne }}$ between different air permeabilities $k^{\mathrm{a}}$ is mainly observed before the plateau period. This is because the change of the radius of vertical drain influenced all period of consolidation process. However, the change of the air permeability of vertical drain 
only had significant influence before the plateau period. After the plateau period, the consolidation process is dominated by water phase.

\section{Summary and Conclusions}

The equal-strain model established in this paper has a negligible difference for average degree of consolidation compared with the free-strain model. Parametric studies regarding wellresistance effect are graphically presented and discussed, and the key findings are summarized as follows:

(1) The solutions calculated from the equal-strain model show good agreement with that obtained from the free-strain model. The main difference between the two models is mainly found at the earlier stage of the consolidation.

(2) The higher the ratio of $k_{\mathrm{r}}^{\mathrm{a}} / k_{\mathrm{r}}^{\mathrm{w}}$ is, the faster the consolidation is. With an increase of consolidation time $T$, the curve of average degree of consolidation for water phase gradually tends to be consistent.

(3) With the increase of $k^{\mathrm{a}} / k^{\mathrm{w}}$, the excess pore-air and -water pressures tend to dissipate faster. After the excess pore-air pressure dissipated almost completely, a plateau period occurs in the excess porewater pressure patterns when $k^{\mathrm{a}} / k^{\mathrm{w}}>1$. It should be noted that the greater the ratio of $k^{\mathrm{a}} / k^{\mathrm{w}}$ is, the longer the plateau gets.

(4) Both the water and air phases of consolidation proceed more quickly with the increase of $r_{\mathrm{w}}$, and the change of the radius of vertical drain influenced all period of consolidation process.

\section{Conflicts of Interest}

The authors declare that they have no conflicts of interest.

\section{References}

[1] K. Terzaghi, Theoretical Soil Mechanics, John Wiley and Sons, New York, NY, USA, 1943.

[2] R. L. Schiffman and J. R. Stein, "One-dimensional consolidation of layered systems," Journal of the Soil Mechanics and Foundations Division, vol. 96, no. 4, pp. 1499-1504, 1970.

[3] J. Zhang, G. Cen, W. Liu, and H. Wu, "One-dimensional consolidation of double-layered foundation with depthdependent initial excess pore pressure and additional stress," Advances in Materials Science and Engineering, vol. 2015, Article ID 618717, 13 pages, 2015.

[4] J. C. Liu, G. H. Lei, and Y. X. Wang, "One-dimensional consolidation of soft ground considering non-Darcy flows," Chinese Journal of Geotechnical Engineering, vol. 33, no. 7, pp. 1117-1122, 2011, in Chinese.

[5] Z. Liu, F. Yan, and X. Wang, "One-dimensional rheological consolidation analysis of saturated clay considering nonDarcy flow," Chinese Journal of Rock Mechanics and Engineering, vol. 32, no. 9, pp. 1937-1944, 2013, in Chinese.

[6] E. Conte and A. Troncone, "One-dimensional consolidation under general time-dependent loading," Canadian Geotechnical Journal, vol. 43, no. 11, pp. 1107-1116, 2006.
[7] S. C. Lu and T. W. Hsu, "Behavior of one-dimensional consolidation under time-dependent loading," Journal of Engineering Mechanics, vol. 132, no. 4, pp. 457-462, 2006.

[8] R. E. Gibson, "A one-dimensional consolidation problem with a moving boundary," Quarterly of Applied Mathematics, vol. 18, no. 2, pp. 123-129, 1960.

[9] W. H. Zhou and L. S. Zhao, "One-dimensional consolidation of unsaturated soil subjected to time-dependent loading with various initial and boundary conditions," International Journal of Geomechanics, vol. 14, no. 2, pp. 291-301, 2014.

[10] K. H. Xie, X. Y. Xie, and W. Jiang, "A study on onedimensional nonlinear consolidation of double-layered soil," Computers and Geotechnics, vol. 29, no. 2, pp. 151168, 2002.

[11] R. P. Chen, W. H. Zhou, H. Z. Wang, and Y. M. Chen, "Onedimensional nonlinear consolidation of multi-layered soil by differential quadrature method," Computers and Geotechnics, vol. 32, no. 5, pp. 358-369, 2005.

[12] G. E. Blight, Strength and Consolidation Characteristics of Compacted Soils, Ph.D. dissertation, University of London, London, UK, 1961.

[13] L. Barden, "Consolidation of compacted and unsaturated clays,” Géotechnique, vol. 15, no. 3, pp. 267-286, 1965.

[14] V. Dakshanamurthy, D. G. Fredlund, and H. Rahardjo, "Coupled three-dimensional consolidation theory of unsaturated porous media," in Proceedings of the 5th International Conference on Expansive Soils, pp. 99-103, Adelaide, SA, Australia, May 1984.

[15] D. G. Fredlund and H. Rahardjo, Soil Mechanics for Unsaturated Soils, John Wiley and Sons, New York, NY, USA, 1993.

[16] D. G. Fredlund and J. U. Hasan, "One-dimensional consolidation theory of unsaturated soils," Canadian Geotechnical Journal, vol. 17, no. 3, pp. 521-531, 1979.

[17] A. F. Qin, G. J. Chen, Y. W. Tan, and D. A. Sun, "Analytical solution to one-dimensional consolidation in unsaturated soils," Applied Mathematics and Mechanics, vol. 29, no. 10, pp. 1329-1340, 2008.

[18] A. F. Qin, D. A. Sun, and Y. W. Tan, "Semi-analytical solution to one-dimensional consolidation in unsaturated soils," Applied Mathematics and Mechanics, vol. 31, no. 2, pp. 215-226, 2009.

[19] Z. D. Shan, D. S. Ling, and H. J. Ding, "Exact solutions for one-dimensional consolidation of single-layer unsaturated soil," International Journal for Numerical and Analytical Methods in Geomechanics, vol. 36, no. 6, pp. 708-722, 2012.

[20] W. H. Zhou, L. S. Zhao, and X. B. Li, "A simple analytical solution to one-dimensional consolidation for unsaturated soils," International Journal for Numerical and Analytical Methods in Geomechanics, vol. 38, no. 8, pp. 794-810, 2013.

[21] L. Ho, B. Fatahi, and H. Khabbaz, "Analytical solution for one-dimensional consolidation of unsaturated soils using eigenfunction expansion method," International Journal for Numerical and Analytical Methods in Geomechanics, vol. 38, no. 10, pp. 1058-1077, 2014.

[22] Z. D. Shan, D. S. Ling, and H. J. Ding, "Analytical solution for 1D consolidation of unsaturated soil with mixed boundary condition," Journal of Zhejiang University Science A, vol. 14, no. 1, pp. 61-70, 2013.

[23] A. F. Qin, D. A. Sun, and Y. W. Tan, "Analytical solution to one-dimensional consolidation in unsaturated soils under loading varying exponentially with time," Computers and Geotechnics, vol. 37, no. 1-2, pp. 233-238, 2010.

[24] L. Ho and B. Fatahi, "One-dimensional consolidation analysis of unsaturated soils subjected to time-dependent loading," 
International Journal of Geomechanics, vol. 16, no. 2, p. 04015052, 2016.

[25] Z. Shan, D. Ling, and H. Ding, "Analytical solution for the 1D consolidation of unsaturated multi-layered soil," Computers and Geotechnics, vol. 57, pp. 17-23, 2014.

[26] E. Conte, "Plane strain and axially symmetric consolidation in unsaturated soils," International Journal of Geomechanics, vol. 6, no. 2, pp. 131-135, 2006.

[27] L. Ho, B. Fatahi, and H. Khabbaz, "A closed form analytical solution for two-dimensional plane strain consolidation of unsaturated soil stratum," International Journal for Numerical and Analytical Methods in Geomechanics, vol. 39, no. 15, pp. 1665-1692, 2015.

[28] L. Ho and B. Fatahi, "Analytical solution for the twodimensional plane strain consolidation of an unsaturated soil stratum subjected to time-dependent loading," Computers and Geotechnics, vol. 67, pp. 1-16, 2015.

[29] A. F. Qin, D. A. Sun, L. P. Yang, and Y. F. Weng, "A semianalytical solution to consolidation of unsaturated soils with the free drainage well," Computers and Geotechnics, vol. 37, no. 7-8, pp. 867-875, 2010.

[30] W. H. Zhou and S. Tu, "Unsaturated consolidation in a sand drain foundation by differential quadrature method," Procedia Earth and Planetary Science, vol. 5, pp. 52-57, 2012.

[31] W. H. Zhou, "Axisymmetric consolidation of unsaturated soils by differential quadrature method," Mathematical Problems in Engineering, vol. 2013, Article ID 497161, 14 pages, 2013.

[32] L. Ho, B. Fatahi, and H. Khabbaz, "Analytical solution to axisymmetric consolidation in unsaturated soils with linearly depth-dependent initial conditions," Computers and Geotechnics, vol. 74, pp. 102-121, 2016.

[33] R. A. Barron, "Consolidation of fine grained soils by drain wells," Transactions of the American Society of Civil Engineers, vol. 113, pp. 718-742, 1948.

[34] K. H. Xie and G. X. Zeng, "Consolidation theories for drain wells under equal strain condition," Chinese Jounal of Geotechnical Engineering, vol. 11, no. 2, pp. 3-17, 1989, in Chinese.

[35] C. J. Leo, "Equal strain consolidation by vertical drains," Journal of Geotechnical and Geoenvironmental Engineering, vol. 130, no. 3, pp. 316-327, 2015.

[36] E. Conte, A. Troncone, and M. Vena, "A method for the design of embedded cantilever retaining walls under static and seismic loading," Géotechnique, vol. 67, no. 12, pp. 1-9, 2017. 


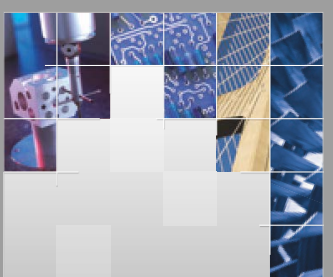

\section{Enfincering}
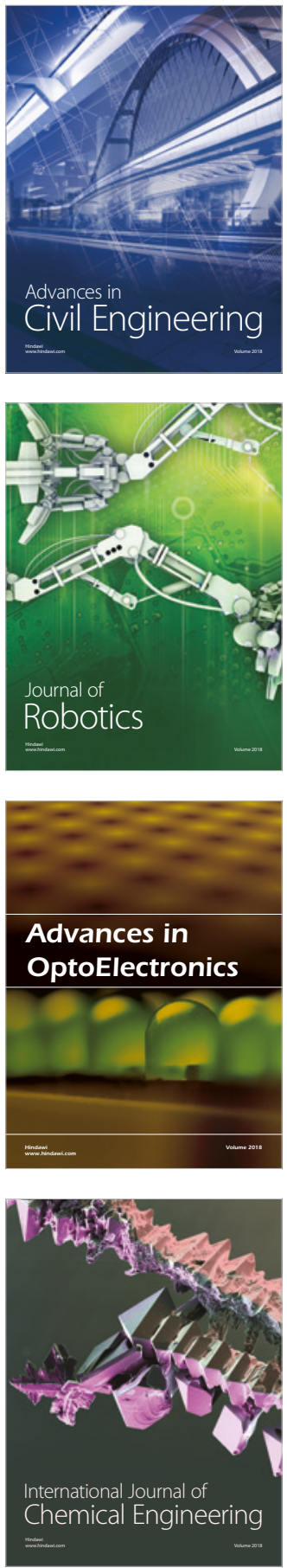

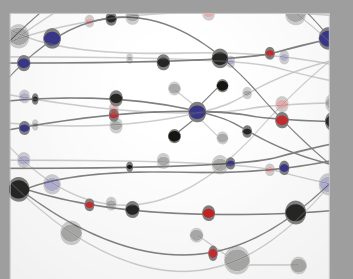

\section{Rotating \\ Machinery}

The Scientific World Journal

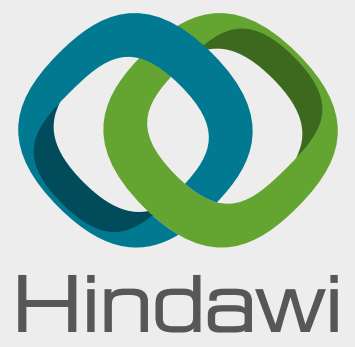

Submit your manuscripts at

www.hindawi.com
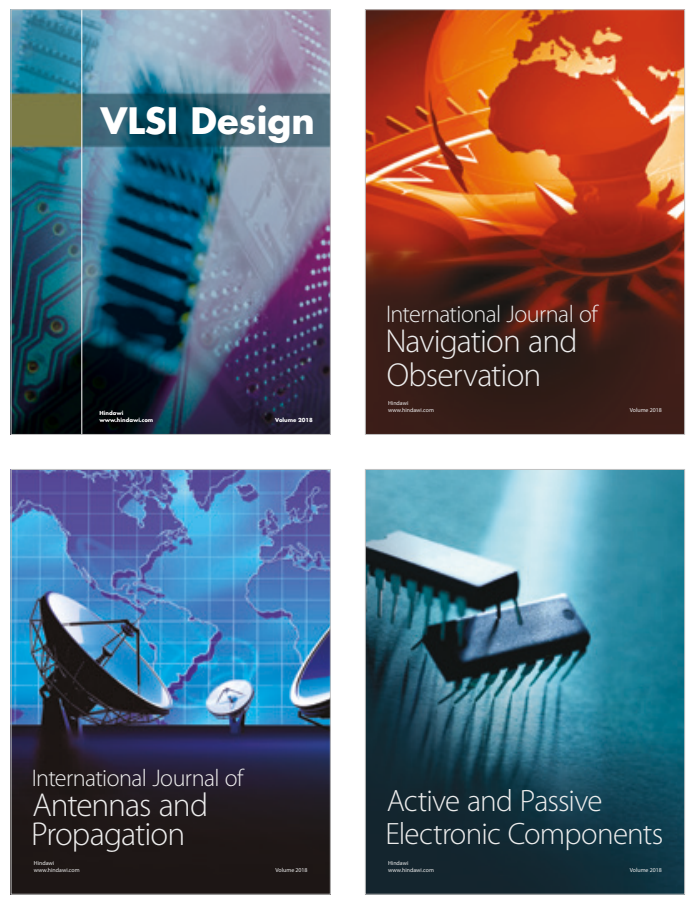
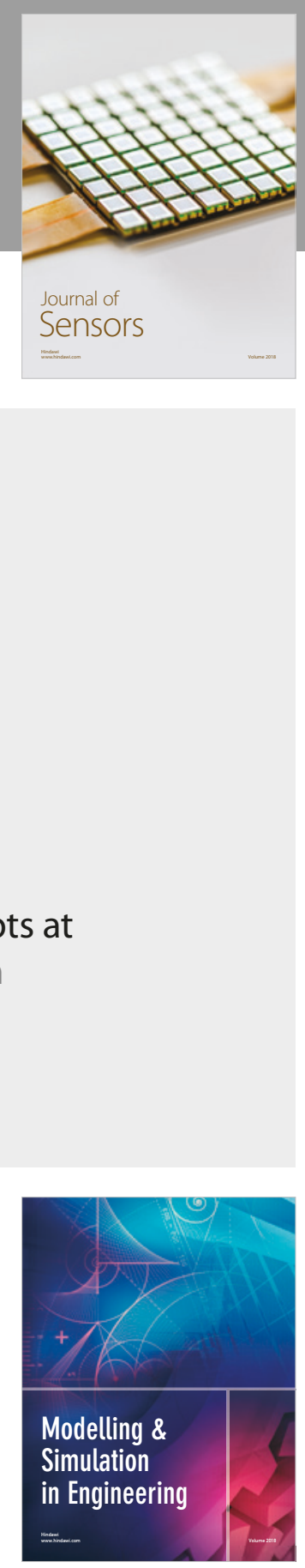

\section{Advances \\ Multimedia}
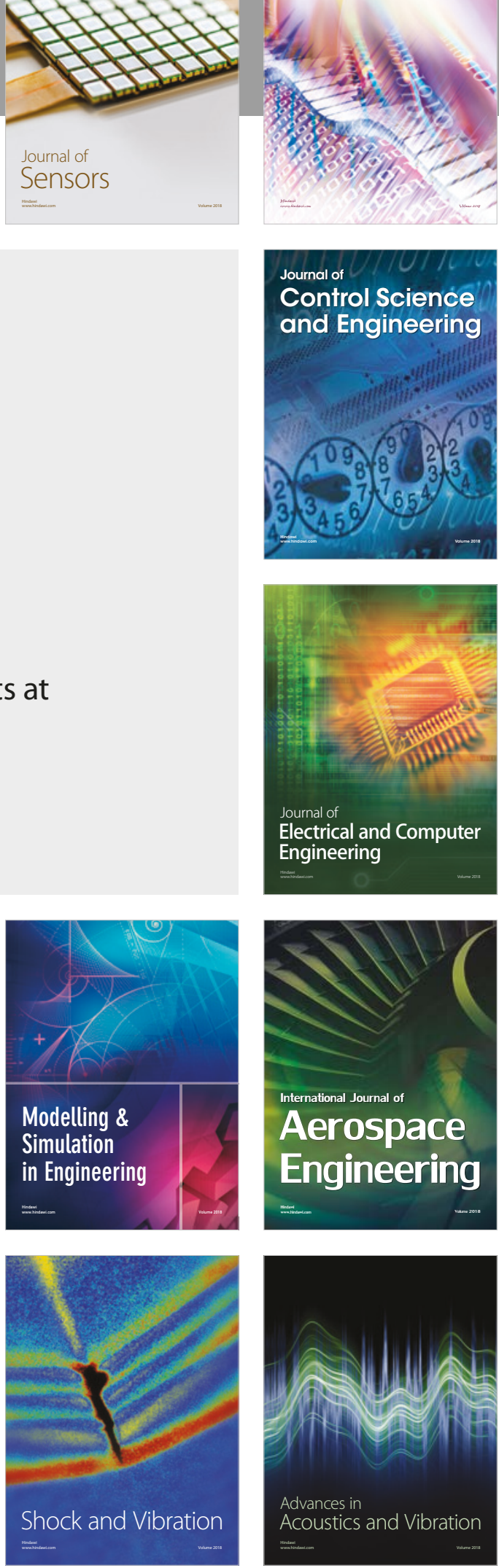